Check for updates

Cite this: RSC Adv., 2019, 9, 29788

Received 26th June 2019

Accepted 14th September 2019

DOI: $10.1039 / c 9 r a 04828 f$

rsc.li/rsc-advances

\section{Biorenewable rosin derived benzocyclobutene resin: a thermosetting material with good hydrophobicity and low dielectric constant $\uparrow$}

\author{
Fei Fu, ${ }^{\text {ab }}$ Dan Wang, ${ }^{\text {ac }}$ Minggui Shen, (D) *ac Shibin Shang, ${ }^{\text {ac }}$ Zhanqian Song $^{\text {a }}$ \\ and Jie Song ${ }^{d}$
}

Development of bio-based polymers has been promoted by the growing concerns about the long-term sustainability and negative environmental footprint of petroleum-based polymer materials. A new monomer containing benzocyclobutene and allyl units has been developed by using rosin as the feedstock. The structure of the monomer was characterized by elemental analysis, MS, FT-IR and NMR spectroscopy. The monomer could be converted to the polymer via thermal ring-opening polymerization which was characterized via FT-IR, thermogravimetric analysis (TGA), atom force microscopy (AFM) and so on. The polymer showed good dielectric properties and hydrophobicity with an average dielectric constant of 2.51 in a range of frequencies from 0.1 to $18 \mathrm{MHz}$ and a water contact angle of $106^{\circ}$. In addition, the polymer with other comprehensive performances exhibited a $5 \%$ weight loss temperature of $406{ }^{\circ} \mathrm{C}$, a surface roughness $\left(R_{\mathrm{a}}\right)$ of $0.658 \mathrm{~nm}$ in a $5.0 \times 5.0 \mu \mathrm{m}^{2}$ area, hardness and Young's modulus of 0.283 and $3.542 \mathrm{GPa}$, and storage modulus of $11.46 \mathrm{GPa}$ at $30{ }^{\circ} \mathrm{C}$. These data suggest that the polymer may have potential application in electronics and microelectronics.

\section{Introduction}

With the rapid development of the military, aerospace and microelectronic industries, high performance polymers are urgently needed. Benzocyclobutene resins, as one family of high performance polymers, have attracted lots of attention in recent years. ${ }^{1-5}$ The monomer benzocyclobutene, in certain circumstances, could undergo ring-opening reaction to provide reactive $o$-quinodimethane, which could undergo dimerization and polymerization, or react with a dienophile to form a Diels-Alder adduct. ${ }^{\mathbf{1 , 3 , 4 , 6 - 1 1}}$ Generally, the resulting benzocyclobutene resins show excellent dielectric properties and thermal stability, and

${ }^{a}$ Institute of Chemical Industry of Forest Products, Chinese Academy of Forestry, Key Laboratory of Biomass Energy and Material, National Engineering Laboratory for Biomass Chemical Utilization, Key and Open Laboratory of Forest Chemical Engineering, State Forestry Administration, Nanjing 210042, Jiangsu Province, China. E-mail: mingguishen@163.com; Fax: +86-25-85482452; Tel: +86-25-85482452 ${ }^{b}$ Co-Innovation Center of Efficient Processing and Utilization of Forest Resources, Nanjing Forestry University, Nanjing 210037, People's Republic of China

'Institute of New Technology of Forestry, Chinese Academy of Forestry, Beijing 100091, China

${ }^{d}$ Department of Chemistry and Biochemistry, University of Michigan-Flint, Flint, Michigan 48502, USA

$\dagger$ Electronic supplementary information (ESI) available: Fig. S1 and S2 are ${ }^{1} \mathrm{H}$ NMR and ${ }^{13} \mathrm{C}$ NMR of Compound 1, respectively. Fig. S3 and S4 are ${ }^{1} \mathrm{H}$ NMR and ${ }^{13} \mathrm{C}$ NMR of Compound 2, respectively. Fig. S5 and S6 are ${ }^{1} \mathrm{H}$ NMR and ${ }^{13} \mathrm{C}$ NMR of Monomer 3, respectively. Fig. S7-S9 are MS of Compound 1, Compound 2 and Monomer 3, respectively. Fig. S10 is DSC trace of the cured resin under $\mathrm{N}_{2}$ at $250{ }^{\circ} \mathrm{C}$ for $2 \mathrm{~h}$. See DOI: $10.1039 / \mathrm{c} 9 \mathrm{ra04828f}$ low water absorption and thermal expansion coefficient. ${ }^{\mathbf{2}}$ Correspondingly, the benzocyclobutene resins have been widely used in the fields of aerospace, electronics and microelectronics, as enameled wire varnish, large scale integrated circuits, composite materials, etc. ${ }^{\mathbf{1 3 - 1 6}}$ Due to the increasingly demanding of the exceptional intermediate layer dielectric materials containing excellent dielectric properties, good hydrophobicity and thermal stability, the benzocyclobutene resins would be further functionalized to satisfy the specific requirement of the performance in some cases. ${ }^{17-19}$ For example, introducing the siloxane group, fluorine-containing group and low polarity bulky group would result in improvements of the dielectric properties and thermal stability.,17-21 However, most of them reveal some defects, for example, the siloxane-based benzocyclobutene resins show excellent thermal stability but they can not lower the dielectric constant very well. ${ }^{10,12,22}$ The fluorinated benzocyclobutene resins usually have low dielectric constant, but they always show poor adhesion to metal and poor dimensional stability. ${ }^{21}$ Increasing the free volume by introducing bulky groups into the polymers can decrease the dielectric constant of the polymers. ${ }^{17}$ Therefore, introducing the low polar bulky functional groups into the polymer turns into the feasible approach for designing and preparation of excellent dielectric materials. ${ }^{21}$

Recently, polymeric materials derived from renewable biomasses such as lignin, cellulose and rosin have received more attention due to their depletion of petroleum resources and the demand of environmental protection. ${ }^{23-28}$ Rosin, a well- 
known biomass with a large hydrogenated phenanthrene ring structure, has been successfully converted to numbers of polymeric materials with excellent thermal, mechanical and hydrophobic properties. ${ }^{29-37}$ Wang et al. introduced rosin into pressure-sensitive adhesive by emulsion polymerization in order to improve the mechanical properties of the copolymer. ${ }^{23}$ El-Ghazawy et al. synthesized a rosin-based epoxy resin used in coatings which showed good thermal stability. ${ }^{32} \mathrm{Xu}$ et al. prepared a rosin-based waterborne polyurethane, and the introduction of rosin structure enhanced the hydrophobicity of the material. ${ }^{36}$ Moreover, the hydrogenated phenanthrene ring structure is bulky, rigid, hydrophobic and low-polar, ${ }^{23,31}$ so the introduction of the structure might improve the thermal stability, hydrophobicity and dielectric properties of benzocyclobutene resins.

In this work, a rosin-based benzocyclobutene monomer had been synthesized by using dehydroabietic acid as raw material. According to the benzocyclobutene reaction mechanism, the monomer containing benzocyclobutene and allyl units could be used as a precursor for the preparation of high performance materials, which exhibited good thermal stability, hydrophobicity and dielectric properties (Scheme 1). These results indicate that the polymer is suitable as encapsulation resin or dielectric material in the field of electronics and microelectronics.

\section{Experimental}

\section{Materials}

Dehydroabietic acid (DA) was obtained from Wuzhou Chemical Co., Ltd. Benzocyclobutene-4-boronic acid was purchased from Chemtarget Technologies Co., Ltd. $N$-Bromosuccinimide (NBS), tripotassium phosphate, Tetrakis(triphenylphosphine)palladium(0), allyl bromide, potassium carbonate and azodiisobutyronitrile (AIBN) were obtained from Aladdin Industrial Corporation. Ethanol, acetonitrile, acetone, xylene, ethyl acetate and petroleum ether were purchased from Nanjing Chemical Reagent Co., Ltd. All chemicals were used without purification.

\section{Measurements}

${ }^{1} \mathrm{H}$ NMR and ${ }^{13} \mathrm{C}$ NMR spectra were recorded on a Bruker 400 spectrometer using TMS as internal standard with DMSO as a solvent at room temperature. Mass spectra (MS) for compounds were recorded on Waters Q-TOF Micro ${ }^{\mathrm{TM}}$ spectrometer and 5973 Network (Agilent) Mass Selective Detector. FT-IR spectra were carried out on a Thermo Scientific Nicolet IS10 spectrometer (Nicolet) by ATR (attenuated total reflectance). Differential scanning calorimetry (DSC) was run using a PerkinElmer Diamond Differential Scanning Calorimeter with temperature increased at a rate of $10{ }^{\circ} \mathrm{C} \min ^{-1}$ in $\mathrm{N}_{2}$ atmosphere. Thermogravimetric analysis (TGA) was performed on a TG209F1 (NETZSCH, Germany) apparatus with a heating rate of $10{ }^{\circ} \mathrm{C} \mathrm{min}^{-1}$ in $\mathrm{N}_{2}$ atmosphere. The contact angle of the cured resin was measured at room temperature using a sessile drop method on a dynamic contact angle measurement instrument (JC2000C). Deionized water was selected as the testing liquid. Surface toughness of the polymer film was measured by atom force microscopy (AFM) on a Shimadzu SPM-9600 (Japan). The dielectric constant and dielectric loss of the cured resin were measured in a range of frequencies from 0.1 to $18 \mathrm{MHz}$ at room temperature using a 4294A Precision Impedance Analyzer (Agilent). The mechanical properties of the cured resin were measured on a nanoindentation system called UNHT (Anton Paar). The phase structure of as-prepared product was characterized with X-ray diffraction (XRD, Bruker D8 advance with $\mathrm{Cu}$ $\mathrm{K} \alpha \lambda=1.5418 \AA$ ). The scans were taken within the $2 \theta$ range between $5^{\circ}$ and $40^{\circ}$ and operated at an accelerating voltage of 40 $\mathrm{kV}$ and an emission current of $40 \mathrm{~mA}$. Dynamic Mechanical Analysis (DMA) of samples was performed in stretching mode

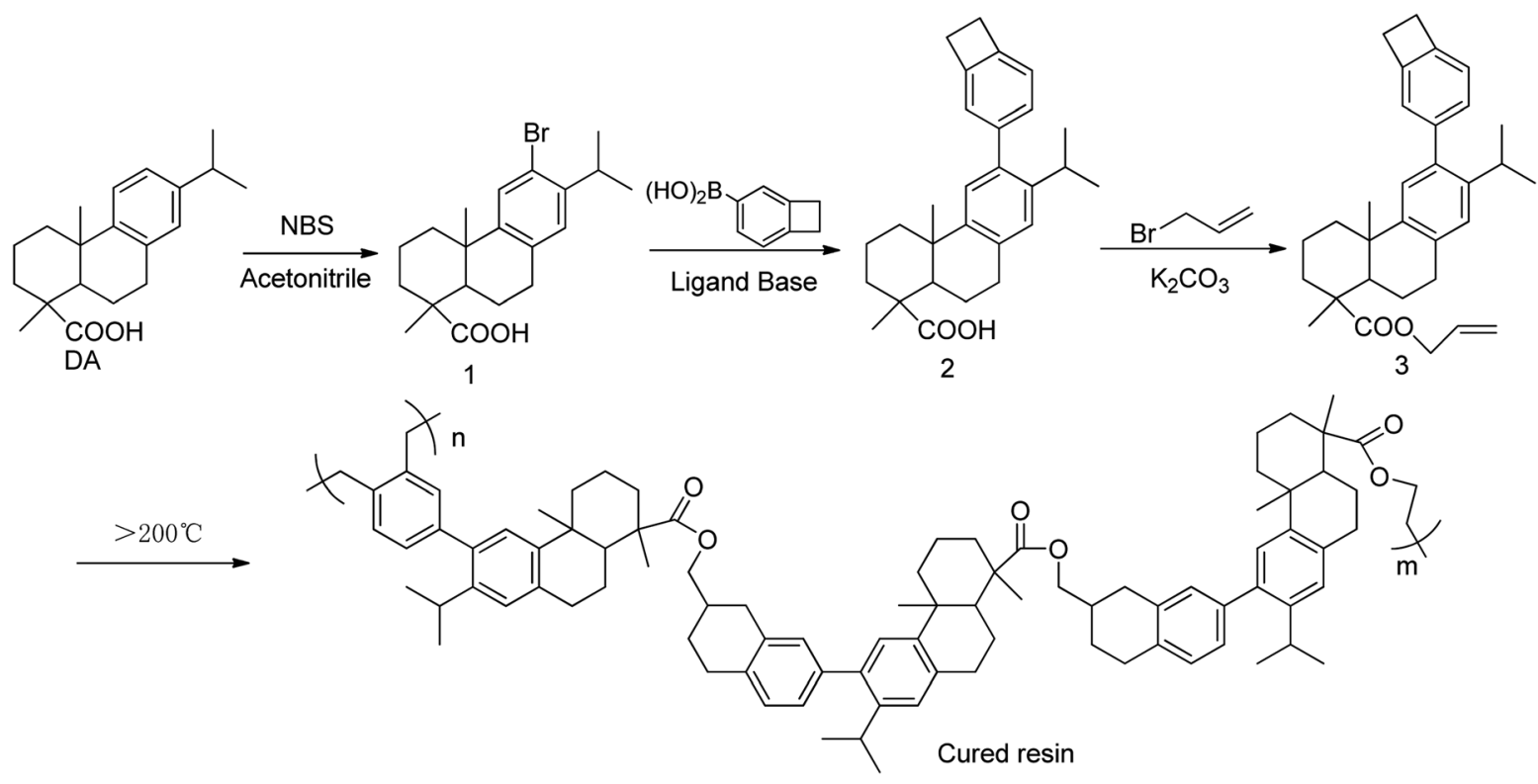

Scheme 1 Procedure for the synthesis of the new monomer and polymer. 
using a DMA Q800 (TA, USA). The frequency was set at $1 \mathrm{~Hz}$, and each sample was scanned from 30 to $300{ }^{\circ} \mathrm{C}$ at a heating rate of $3{ }^{\circ} \mathrm{C} \mathrm{min}^{-1}$. Elemental analysis was performed as $\mathrm{C} / \mathrm{H}$ analyses on an elemental analyzer (PE-2400, PE, USA).

\section{Synthesis of Compound 1}

Dehydroabietic acid (0.017 mol, $5.00 \mathrm{~g})$ was dissolved in anhydrous acetonitrile $(337 \mathrm{~mL})$, and NBS $(0.031 \mathrm{~mol}, 5.54 \mathrm{~g})$ was added. Then the mixture was reacted in darkness at room temperature for $24 \mathrm{~h}$. The mixture was suction filtered, yielding a white solid that was dissolved in ethyl acetate $(50 \mathrm{~mL})$. The organic phase was then washed with water $(50 \mathrm{~mL}, \times 3)$ and dried over anhydrous $\mathrm{Na}_{2} \mathrm{SO}_{4}$. After filtration and concentration, Compound $\mathbf{1}$ was purified using column chromatography with a mixture of petroleum ether and ethyl acetate as the eluent (5 : 1, v/v). ${ }^{1} \mathrm{H}$ NMR (400 MHz, DMSO) $\delta 12.20$ (s, 1H), 7.36 (s, $1 \mathrm{H}), 7.00(\mathrm{~s}, 1 \mathrm{H}) .{ }^{13} \mathrm{C}$ NMR (101 MHz, DMSO) $\delta 179.24(\mathrm{~m})$, 149.21 (s), 143.23 (s), 134.51 (s), 127.95 (s), 127.20 (s), 120.79 (m), 46.23 (s), 44.24 (s), 37.48 (s), 36.53 (s), 36.13 (s), 31.92 (s), 28.89 (s), 24.55 (s), 22.68 (s), 22.59 (s), 20.77 (m), 18.02 (s), 16.30 (s). Anal. calcd. for $\mathrm{C}_{20} \mathrm{H}_{27} \mathrm{BrO}_{2}$ : C 63.33, $\mathrm{H}$ 7.17; found: $\mathrm{C}$ 64.22, H 7.10.

\section{Synthesis of Compound 2}

Under nitrogen atmosphere, Compound 1 (1.00 mmol, $0.379 \mathrm{~g}$ ), benzocyclobutene-4-boronic acid (1.25 mmol, $0.185 \mathrm{~g})$ and tripotassium phosphate $(2.00 \mathrm{mmol}, 0.425 \mathrm{~g})$ were dissolved in an ethanol/water mixture $(6 \mathrm{~mL}, 1: 1, \mathrm{v} / \mathrm{v})$. Then tetrakis(triphenylphosphine)palladium $(0)(0.01 \mathrm{mmol}, 0.0116 \mathrm{~g})$ was added before the mixture was heated at $60{ }^{\circ} \mathrm{C}$ for $10 \mathrm{~h}$. The mixture was cooled to room temperature and suction filtered with diatomite. The filtrate was then extracted with ethyl acetate $(30 \mathrm{~mL}, \times 2)$. The organic phases were combined, washed with water $(50 \mathrm{~mL}, \times 3)$, dried over anhydrous $\mathrm{Na}_{2} \mathrm{SO}_{4}$, filtered and concentrated to afford the crude product. Compound 2 was purified using column chromatography with a mixture of petroleum ether and ethyl acetate as the eluent $(5: 1, \mathrm{v} / \mathrm{v}) \cdot{ }^{1} \mathrm{H}$ NMR (400 MHz, DMSO) $\delta 12.16(\mathrm{~s}, 1 \mathrm{H}), 7.10(\mathrm{~d}, J=7.5 \mathrm{~Hz}, 1 \mathrm{H})$, $7.02(\mathrm{dd}, J=7.5,0.9 \mathrm{~Hz}, 1 \mathrm{H}), 7.00(\mathrm{~s}, 1 \mathrm{H}), 6.93(\mathrm{~s}, 1 \mathrm{H}), 6.91(\mathrm{~s}$, 1H), 3.18 (s, 4H). ${ }^{13} \mathrm{C}$ NMR (101 MHz, DMSO) $\delta 179.35$ (s), 146.27 (s), 144.87 (s), 143.43 (s), 142.46 (s), 140.55 (s), 138.94 (s), 133.51 (s), $127.71(\mathrm{~s}), 125.42$ (s), 125.26 (s), 123.19 (s), 122.01 (s), 46.33 (s), 44.58 (s), 37.70 (s), 36.33 (s), 36.23 (s), 29.16 (s), 29.04 (s), 28.85 (s), 28.34 (s), 24.77 (s), 24.19 (s), 23.99 (s), 21.09 (s), 18.09 (s), 16.32 (s). Anal. calcd. for $\mathrm{C}_{28} \mathrm{H}_{34} \mathrm{O}_{2}$ : C 83.54, $\mathrm{H}$ 8.51; found: $\mathrm{C}$ $82.55, \mathrm{H} 8.96$.

\section{Synthesis of Monomer 3}

Into a $100 \mathrm{~mL}$ three-necked round-bottom flask equipped with reflux condenser were charged Compound 2 (1.56 mmol, 0.680 $\mathrm{g}), \mathrm{K}_{2} \mathrm{CO}_{3}$ (2.56 mmol, $0.216 \mathrm{~g}$ ) and acetone $(10 \mathrm{~mL})$. A solution of allyl bromide (3.12 mmol, $0.377 \mathrm{~g}$ ) dissolved in acetone (5.0 $\mathrm{mL}$ ) was added dropwise at $50{ }^{\circ} \mathrm{C}$. Then the mixture was refluxed at $70{ }^{\circ} \mathrm{C}$ for $12 \mathrm{~h}$. The mixture was cooled to room temperature and filtered before being diluted with ethyl acetate $(50 \mathrm{~mL})$. The solution was washed with water $(50 \mathrm{~mL}, \times 3)$, dried over anhydrous $\mathrm{Na}_{2} \mathrm{SO}_{4}$. After removal of the solvent, the crude product was obtained. Monomer 3 was purified using column chromatography with a mixture of petroleum ether and ethyl acetate as the eluent $(10: 1, \mathrm{v} / \mathrm{v}) .{ }^{1} \mathrm{H}$ NMR (400 MHz, DMSO) $\delta 7.09(\mathrm{~d}, J=7.5 \mathrm{~Hz}, 1 \mathrm{H}), 7.02(\mathrm{~s}, 1 \mathrm{H}), 6.99(\mathrm{~s}, 1 \mathrm{H}), 6.92(\mathrm{~s}, 1 \mathrm{H})$, $6.91(\mathrm{~s}, 1 \mathrm{H}), 5.92$ (ddd, $J=22.6,10.7,5.4 \mathrm{~Hz}, 1 \mathrm{H}), 5.30$ (dd, $J=$ $17.2,1.5 \mathrm{~Hz}, 1 \mathrm{H}$ ), 5.21 (dd, $J=10.5,1.2 \mathrm{~Hz}, 1 \mathrm{H}), 4.56$ (ddd, $J=$ 27.4, 13.6, 5.4 Hz, 2H), 3.16 (s, 4H). ${ }^{13} \mathrm{C}$ NMR (101 MHz, DMSO) $\delta 177.00$ (s), 146.06 (s), 144.85 (s), 143.43 (s), 142.54 (s), 140.52 (s), 139.03 (s), 133.38 (s), 132.78 (s), 127.68 (s), 125.43 (s), 125.30 (s), $123.17(\mathrm{~s}), 121.99(\mathrm{~s}), 117.64(\mathrm{~s}), 64.58(\mathrm{~s}), 47.00(\mathrm{~s}), 44.73(\mathrm{~s})$, 37.59 (s), 36.41 (s), 36.15 (s), 29.16 (s), 29.03 (s), 28.85 (s), 28.34 (s), 24.85 (s), 24.15 (s), 23.98 (s), 21.12 (s), 18.00 (s), 16.27 (s). Anal. calcd. for $\mathrm{C}_{31} \mathrm{H}_{38} \mathrm{O}_{2}$ : C 84.12, $\mathrm{H}$ 8.65; found: $\mathrm{C} 83.46, \mathrm{H}$ 8.90 .

\section{Preparation of benzocyclobutene polymers}

Monomer 3 was placed in a glass mold filled with nitrogen. The mold was placed in a tube furnace for heating. Then the temperature was elevated and kept at $180{ }^{\circ} \mathrm{C}$ for $6.0 \mathrm{~h}, 210^{\circ} \mathrm{C}$ for $1.0 \mathrm{~h}, 230{ }^{\circ} \mathrm{C}$ for $1.5 \mathrm{~h}, 250{ }^{\circ} \mathrm{C}$ for $1.5 \mathrm{~h}$ and $290{ }^{\circ} \mathrm{C}$ for $0.5 \mathrm{~h}$, respectively. A completely cured sample was thus prepared, which was used to measure dynamic mechanical, dielectric properties and for nanoindentation tests.

A solution of Monomer 3 dissolved in xylene $\left(35 \mathrm{mg} \mathrm{mL}^{-1}\right)$ was spin-coated on a monocrystalline silicon wafer to form a smooth film which was dried for $24 \mathrm{~h}$ at room temperature. The silicon wafer was placed into a tube furnace and heated stepwise at $180^{\circ} \mathrm{C} / 1.0 \mathrm{~h}, 210^{\circ} \mathrm{C} / 1.0 \mathrm{~h}, 230^{\circ} \mathrm{C} / 1.5 \mathrm{~h}, 250^{\circ} \mathrm{C} / 1.5 \mathrm{~h}$ and $290{ }^{\circ} \mathrm{C} / 0.5 \mathrm{~h}$. After cooling down to room temperature, the sample was used for the measurement of surface toughness.

\section{Results and discussion}

\section{Synthesis and characterization}

As shown in Scheme 1, the functional Monomer 3 was prepared via a three-step procedure by using dehydroabietic acid as the feedstock. The chemical structure of the monomer was confirmed by ${ }^{1} \mathrm{H}$ NMR, ${ }^{13} \mathrm{C}$ NMR, MS, FT-IR and elemental analysis. In its ${ }^{1} \mathrm{H}$ NMR spectrum (Fig. 1), the signals from $0.5 \mathrm{ppm}$ to $3.0 \mathrm{ppm}$ were all attributed to the protons attached on the hydrogenated phenanthrene ring; ${ }^{38}$ the peaks at $5.92 \mathrm{ppm}, 5.21-5.30 \mathrm{ppm}$ and $4.56 \mathrm{ppm}$ were assigned to the protons on the terminal $-\mathrm{CH}_{2}-\mathrm{CH}=\mathrm{CH}_{2}$ groups; the signals from 6.91-7.09 ppm were all attributed to the protons attached on the benzene ring, and the characteristic peak at $3.16 \mathrm{ppm}$ belonged to the protons on the four-membered ring of benzocyclobutene. FT-IR of Monomer 3 was shown in Fig. 2. As could be seen in Fig. 2, the absorption peaks at 1467, 934, $833 \mathrm{~cm}^{-1}$ were ascribing to the in-plane ring stretching vibration of $\mathrm{C}-\mathrm{H}$ in the four-member ring of benzocyclobutene group; ${ }^{17}$ the signals at 1644, 997, $907 \mathrm{~cm}^{-1}$ in Monomer 3, were assigned to the characteristic peak for allyl group. In addition, the characteristic peak for ester group was observed at $1710 \mathrm{~cm}^{-1} \cdot{ }^{1} \mathrm{H}$ $\mathrm{NMR},{ }^{13} \mathrm{C}$ NMR, MS of synthetic compounds were described in ESI. $\dagger$ Thus, all data were consistent with the proposed, 
<smiles>CC(C)c1cc2c(cc1-c1ccc3c(c1)CI3I)C1(C)CCCC(C)(C(=O)OCC=O)C1CC2</smiles>

$\mathrm{i}-\mathrm{j}$

Fig. $1{ }^{1} \mathrm{H}$ NMR spectra of the monomer.

exhibiting that the chemical structure of Monomer 3 had been confirmed.

\section{Curing behavior}

It is noted that the target monomer can react via radical polymerization and ring-opening polymerization, because the monomer contains allyl and benzocyclobutene groups. In order to understand the structural characteristics of Monomer 3, a DSC trace of monomer with AIBN was carried out, and the results were

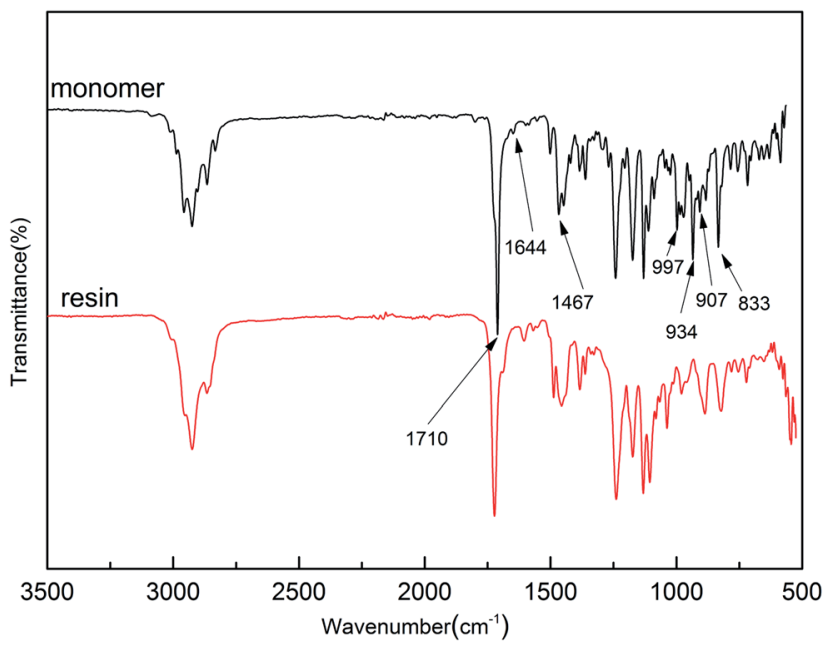

Fig. 2 FT-IR spectra of the monomer and resin. shown in Fig. 3. The endothermic peak indicating melting of monomer was observed at $100{ }^{\circ} \mathrm{C}$. In addition, the radical polymerization started at about $103{ }^{\circ} \mathrm{C}$ and gave an exothermic peak at the temperature about $123{ }^{\circ} \mathrm{C}$. When the temperature was raised above $200{ }^{\circ} \mathrm{C}$, a broad exotherm was observed, which was attributed to the ring-opening reaction of benzocyclobutene units. The radical polymerization and thermally ring-opening polymerization of Monomer 3 are similar to that of the polymers containing vinyl units and benzocyclobutene groups. ${ }^{28}$

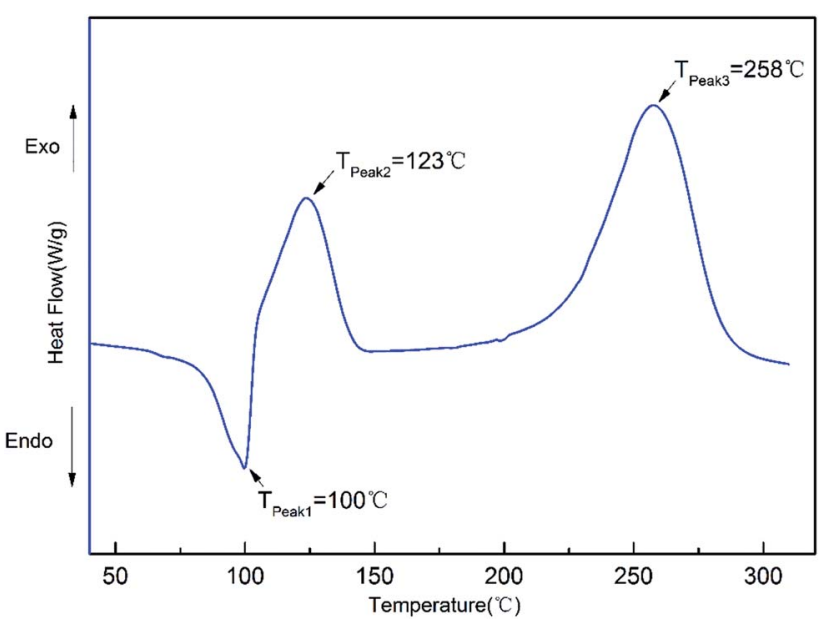

Fig. 3 DSC curve of Monomer 3 at a heating rate of $10^{\circ} \mathrm{C} \mathrm{min}^{-1}$ in $\mathrm{N}_{2}$. 
The polymerization degree of the monomer was also estimated by DSC trace (ESI, Fig. S10 $\dagger$ ). After the cured resin was maintained at $250{ }^{\circ} \mathrm{C}$ for $2 \mathrm{~h}$, the DSC trace indicated that no exothermic peak was observed, suggesting that the polymerization had been completed.

The curing reaction of Monomer 3 was detected by FT-IR spectra. The difference of FT-IR spectra between monomer and cured resin were shown in Fig. 2. In their FT-IR spectra, the characteristic peaks for benzocyclobutene group at 1467, 934, $833 \mathrm{~cm}^{-1}$ and the signals for allyl group at 1644, 997, $907 \mathrm{~cm}^{-1}$ disappeared after monomer curing. These results suggested that monomer had fully converted to cured resin.

\section{Thermal stability}

The thermostability of the cured resin was investigated using thermogravimetric analysis (TGA). The TG and DTG curves for the cured resin are shown in Fig. 4 and 5 . The $T_{5 \%}$ and $T_{10 \%}$ values are chosen as the measure of thermal stability, which represent the temperature at five percent and ten percent mass loss. ${ }^{21}$ As shown in Fig. 4 , the $T_{5 \%}$ and $T_{10 \%}$ of the cured resin are $406{ }^{\circ} \mathrm{C}, 416{ }^{\circ} \mathrm{C}$, respectively. Moreover, the temperature of the highest mass loss occur is $450{ }^{\circ} \mathrm{C}$ (Fig. 5). These results indicate that the cured resin has good thermal stability.

\section{Hydrophobic property}

Hydrophobic property is an important parameter for the application of high performance material. The hydrophobicity of the cured resin was investigated by the water contact angle test. The water contact angle is measured as $106^{\circ}$ (Fig. 6). The result indicates the resin has good hydrophobicity because of the introduction of the hydrogenated phenanthrene ring. As a hydrophobic group, the introduction of the hydrogenated phenanthrene ring can improve the hydrophobicity of polymeric materials. ${ }^{36,37}$ The high hydrophobicity is required for the production of devices in the electronics and microelectronics, because it can prevent the moisture adsorption and the deterioration of the dielectric properties effectively.

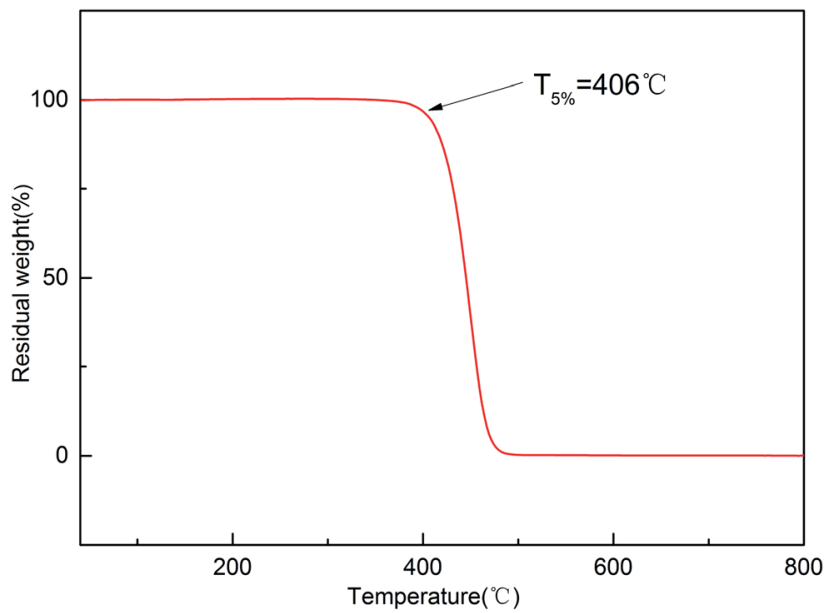

Fig. 4 TG curve of the cured resin in $\mathrm{N}_{2}$ with a heating rate of $10{ }^{\circ} \mathrm{C} \mathrm{min}^{-1}$

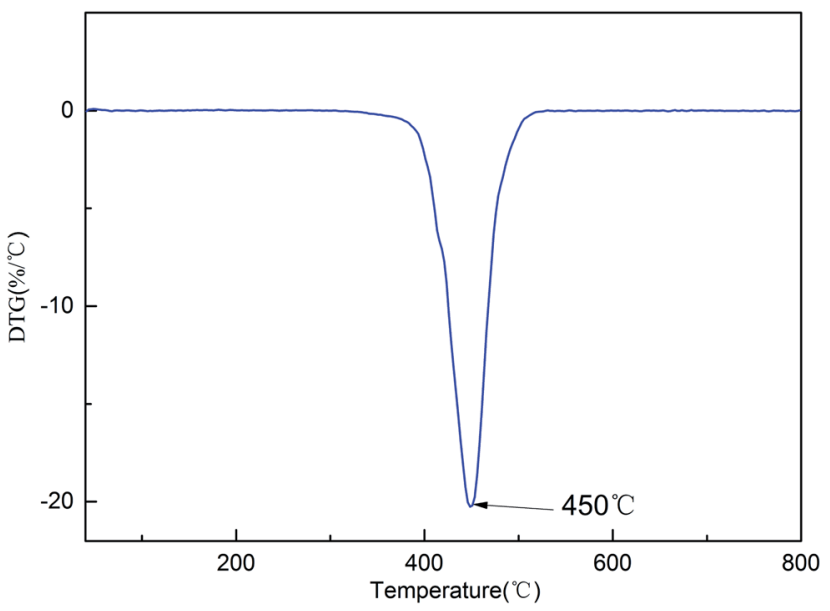

Fig. 5 DTG curve of the cured resin in $\mathrm{N}_{2}$ with a heating rate of $10^{\circ} \mathrm{C} \mathrm{min}^{-1}$.

\section{Surface roughness}

Some of thermally cross-linked polymers or oligomers showed shrinkage leading to greater surface roughness when they were treated at high temperature, such as epoxy and phenolic resins. ${ }^{16}$ However, surface roughness is more crucial for the materials utilized in electronic and microelectronic industry, because low surface roughness implies that the array with high quality can be easily produced on the film surface. ${ }^{28}$ In general, the benzocyclobutene-based resin exhibits good surface roughness. ${ }^{6,19,39}$ Surface roughness of the polymer castings on a silicon wafer was investigated by atomic force microscopy (AFM). Both planar graph and stereogram are shown in Fig. 7. Measurement results show that the average surface roughness $R_{\mathrm{a}}$ of the cured resin is $0.658 \mathrm{~nm}$ in a $5.0 \times 5.0 \mu \mathrm{m}^{2}$ area. The good surface roughness indicates that the cured resin is appropriate for application in the electronic and microelectronic fields. ${ }^{28}$

\section{Dielectric properties}

The dielectric properties of the cured resin were measured. The results are shown in Fig. 8. As can be seen form Fig. 8, the cured resin shows average dielectric constant $(k)$ of 2.51 and dielectric loss $(\tan \delta)$ of below $5.0 \times 10^{-3}$ in a range of frequencies varying from 0.1 to $18 \mathrm{MHz}$ at room temperature. These results show

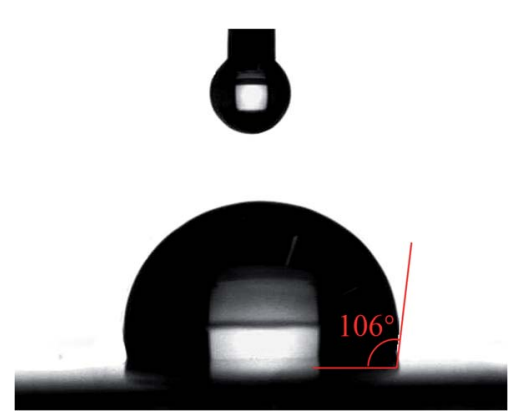

Fig. 6 Contact angle of water on the cured resin. 

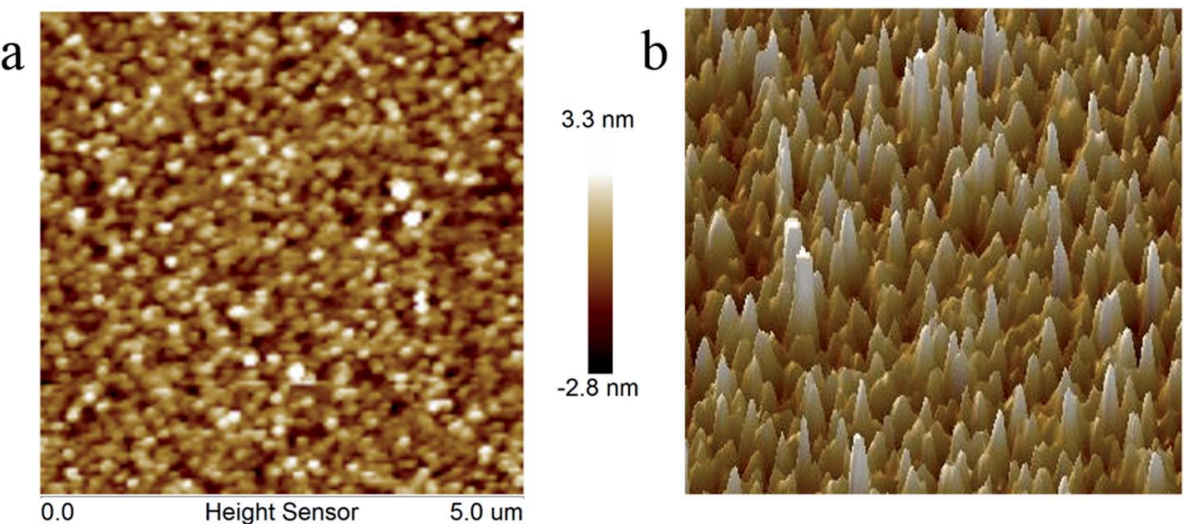

Fig. 7 AFM images of the cured resin film: (a) planar graph and (b) stereogram.

that the cured resin has excellent dielectric properties. It is noted that the $k$ value of the cured resin is better than the commercially available organic low- $k$ materials, such as polyimides (3.1-3.4), ${ }^{\mathbf{4 0 , 4 1}}$ SILK resins $(2.65)^{\mathbf{4 2}}$ and polycyanate esters $(2.61-3.12) .{ }^{43}$

The reason why the cured resin shows good dielectric properties can be explained by the Debye equation, as shown in eqn (1): ${ }^{44}$

$$
\frac{k-1}{k+2}=\frac{4 \pi}{3} N\left(\alpha_{\mathrm{e}}+\alpha_{\mathrm{d}}+\frac{u}{3 k_{\mathrm{b}} T}\right)
$$

where $k$ is dielectric constant, $N$ is the number density of dipoles, $\alpha_{\mathrm{e}}$ is the electric polarization, $\alpha_{\mathrm{d}}$ is the distortion polarization, $\mu$ is the orientation polarization related to the dipole moment, $k_{\mathrm{b}}$ is the Boltzmann constant, and $T$ is the temperature. For the cured resin, the bulky hydrogenated phenanthrene ring structure moieties prevented molecular stacking to increase the free volume of the polymer, thus diminishing $N$. Moreover, the structure is low polar, resulting in the reduction of $\alpha_{\mathrm{e}}$. Usually, the anisotropy is tiny as to amorphous structure of polymers, as a result, the corresponding $\mu$ are small. ${ }^{44} \mathrm{X}$-ray diffraction (XRD) patterns (Fig. 9) indicate that the cured resin is essentially amorphous and molecular

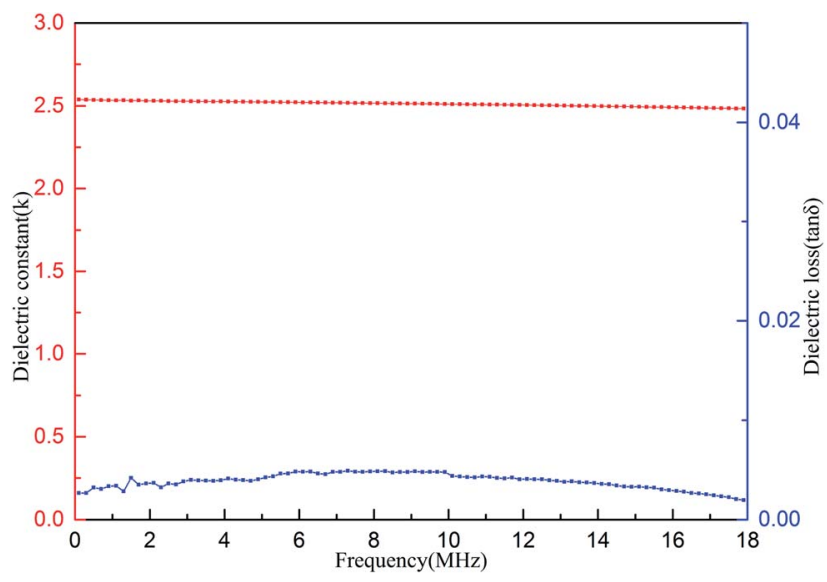

Fig. 8 Dielectric constant and dielectric loss of the cured resin. stacking is prevented. Thus, the reduction of the three factors $\left(N, \alpha_{\mathrm{e}}\right.$ and $\mu$ ) causes the low dielectric constants of the polymer. Moreover, the XRD peak $(2 \theta)=15.5^{\circ}$ corresponds to the $d$ value of $0.571 \mathrm{~nm}$ for the cured resin. The large $d$ spacing indicates the large free volume, endowing the polymer with low $k$ value. $^{21,44}$

\section{Nanoindentation analysis}

Nanoindentation was used to examine the mechanical properties of the cured resin by analyzing Young's modulus and hardness. ${ }^{45}$ Young's modulus, the most important parameters characterizing mechanical rigidity of materials, can be calculated from eqn (2): ${ }^{\mathbf{4 5 - 4 7}}$

$$
\frac{1}{E_{\mathrm{r}}}=\frac{1-\nu}{E}+\frac{1-\nu_{\mathrm{i}}}{E_{\mathrm{i}}}
$$

where $E_{\mathrm{i}}$ and $\nu_{\mathrm{i}}$ are Young's modulus (1141 GPa) and Poisson's rate $(0.07)$ of a diamond indenter, $E_{\mathrm{r}}$ is the reduced elastic modulus, $E$ and $\nu$ are Young's modulus and Poisson's ratio of a sample, respectively, and $\nu$ is taken as 0.34 for polymer materials. ${ }^{39}$ Sample's hardness $(H)$ can be determined by dividing the peak load $\left(P_{\max }\right)$ by contact area $(A)$, eqn $(3):^{45-47}$

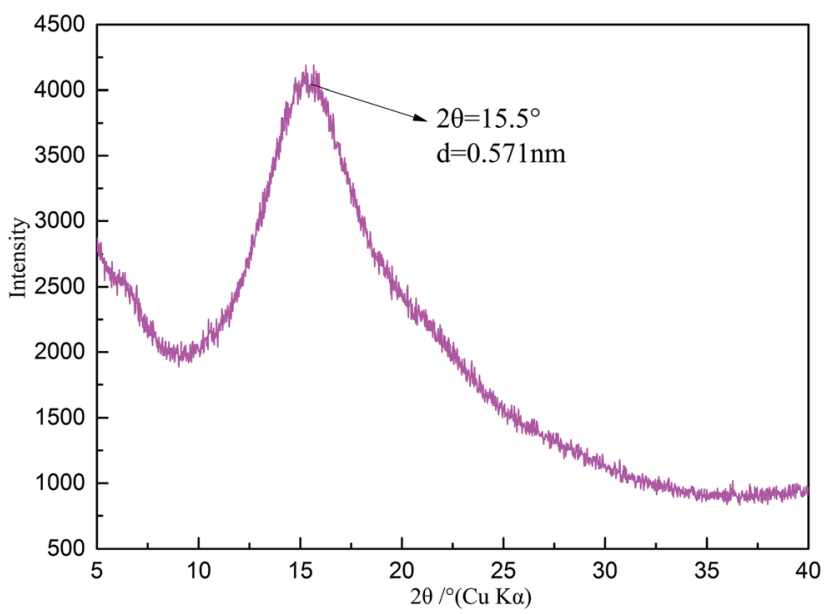

Fig. 9 X-ray diffraction (XRD) patterns of the cured resin (powder). 


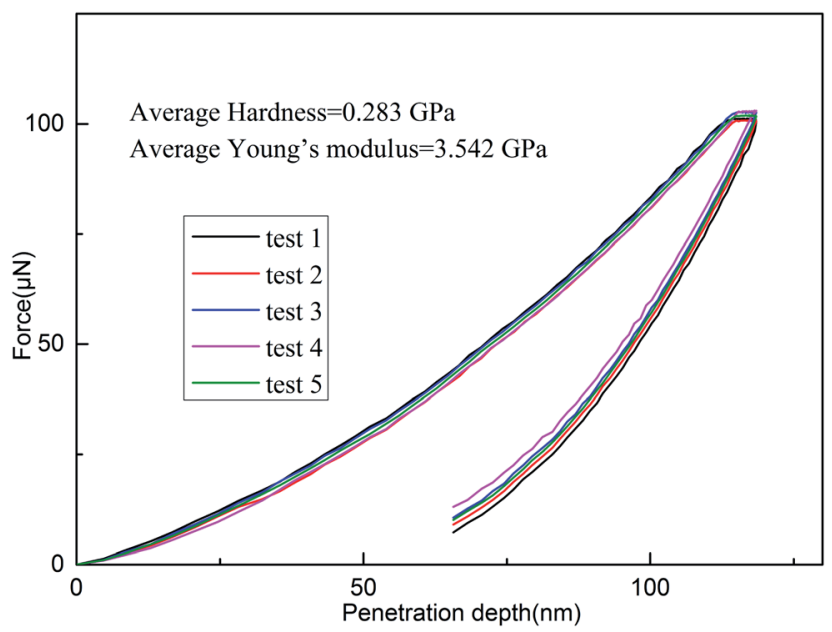

Fig. 10 Results from nanoindentation tests for the cured resin.

$$
H=\frac{P_{\max }}{A}
$$

As depicted in Fig. 10, the cured resin shows that it has an average hardness of $0.283 \mathrm{GPa}$ and Young's modulus of $3.542 \mathrm{GPa}$. Those results suggest that the cured resin is satisfactory as the encapsulation resins for integrated circuit dies for application in the microelectronic industry.

\section{Dynamic mechanical properties}

The dynamic mechanical properties of the cured resin investigated using Dynamic Mechanical Analysis (DMA). The DMA curves of the cured resin are shown in Fig. 11, the cured resin exhibits high storage modulus with storage modulus at $30^{\circ} \mathrm{C}$ of $11.46 \mathrm{GPa}$. The storage modulus of the resin remains almost unchanged with the increase in temperature in a wide range from 30 to $225{ }^{\circ} \mathrm{C}$. The high storage modulus of the resin is caused by the rigid structural unit of the polymer. Moreover, the glass transition temperature $\left(T_{\mathrm{g}}\right)$ of the cured resin is $261{ }^{\circ} \mathrm{C}$, taken as the peak temperature in $\tan \delta$ curve.

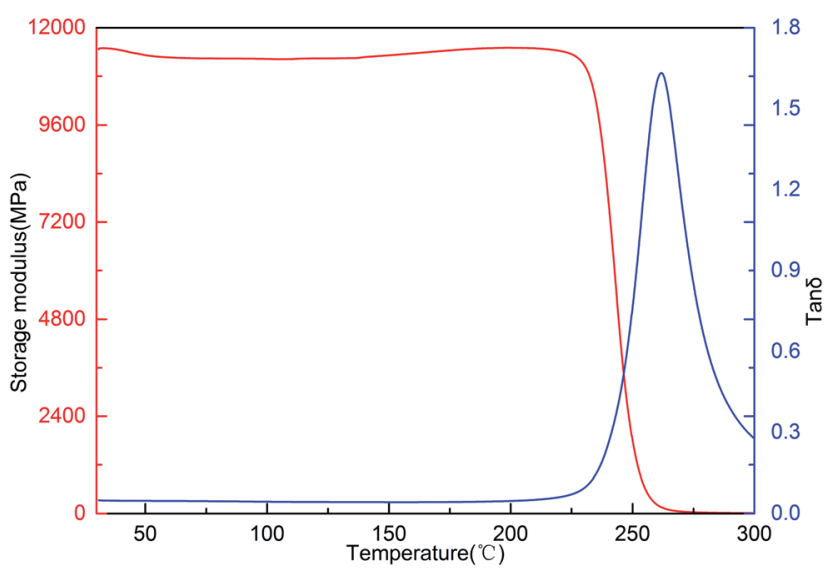

Fig. 11 DMA curves of the cured resin.

\section{Conclusions}

In summary, a new thermosetting resin derived from rosin acid has been successfully synthesized. After polymerization at high temperature, the monomer formed an insoluble and infusible polymer. TGA indicated that the polymer had $T_{5 \%}, T_{10 \%}$ of $406{ }^{\circ} \mathrm{C}$ and $416{ }^{\circ} \mathrm{C}$, respectively. AFM results indicated that the cured resin had the surface roughness $\left(R_{\mathrm{a}}\right)$ of $0.658 \mathrm{~nm}$ in a 5.0 $\times 5.0 \mu \mathrm{m}^{2}$ area, indicating that the polymer film had good surface smoothness and hydrophobicity. Nanoindentation tests and DMA results showed the polymer possessed good mechanical properties, with hardness, Young's modulus and storage modulus of $0.283,3.54$, and $11.46 \mathrm{GPa}$, respectively. Moreover, the polymer exhibited excellent dielectric properties with average dielectric constant of 2.51 varying from 0.1 to 18 $\mathrm{MHz}$ at room temperature. These results indicate that the thermosetting polymer derived from rosin acid is suitable for fields of aerospace, electronics and microelectronics, such as enameled wire varnish, very large scale integrated circuits, fiber reinforced composite materials and interlayer dielectrics in semiconductor packages.

\section{Conflicts of interest}

The authors declare no conflict of interest.

\section{Acknowledgements}

This work was supported by the Fundamental Research Funds of CAF (CAFYBB2017SY035), Natural Science Foundation of Jiangsu Province of China (BK20150071) and National Science Foundation of China (31500487).

\section{References}

1 J. Tong, S. Diao, K. Jin, C. Yuan, J. Wang, J. Sun and Q. Fang, Polymer, 2014, 55, 3628.

2 Y. Cheng, J. Yang, Y. Jin, D. Deng and F. Xiao, Macromolecules, 2012, 45, 4085.

3 K. Cao, L. Yang, Y. Huang, G. Chang and J. Yang, Polymer, 2014, 55, 5680.

4 L. S. Tan, N. Venkatasubramanian, P. T. Mather, M. D. Houtz and C. L. Benner, J. Polym. Sci., Part A: Polym. Chem., 1998, 36, 2637.

5 Y. Huang, S. Zhang, H. Hu, X. Wei, H. Yu and J. Yang, Polym. Adv. Technol., 2017, 28, 1480.

6 C. O. Hayes, P. H. Chen, R. Thedford, C. J. Ellison, G. Dong and C. Willson, Macromolecules, 2016, 49, 3706.

7 Z. J. Wei, Y. W. Xu, L. Zhang and M. M. Luo, Chin. Chem. Lett., 2014, 25, 1367.

8 A. P. Gies, L. Spencer, N. J. Rau, P. Boopalachandran, M. A. Rickard, K. L. Kearns and N. T. McDougal, Macromolecules, 2017, 50, 2304.

9 J. Yang, S. Liu, F. Zhu, Y. Huang, B. Li and L. Zhang, J. Polym. Sci., Part A: Polym. Chem., 2015, 49, 381.

10 J. Yang, Y. Cheng and F. Xiao, Eur. Polym. J., 2012, 48, 751. 11 M. F. Farona, Prog. Polym. Sci., 1996, 21, 505. 
12 Y. Cheng, S. Tian, Y. Shi, W. Chen, Z. Li, T. Zhu and Z. Zhang, Eur. Polym. J., 2017, 95, 440.

13 Y. Cheng, L. Kong, Z. Ren and T. Qi, High Perform. Polym., 2013, 25, 980.

14 Y. Huang, S. Zhang, H. Hu, X. Wei, H. Yu and J. Yang, J. Polym. Sci., Part A: Polym. Chem., 2017, 55, 1920.

15 L. Yang, K. Cao, Y. Huang, G. Chang, F. Zhu and J. Yang, High Perform. Polym., 2014, 26, 463.

16 S. Tian, J. Sun, K. Jin, J. Wang, F. He, S. Zheng and Q. Fang, ACS Appl. Mater. Interfaces, 2014, 6, 20437.

17 F. He, C. Yuan, K. Li, S. Diao, K. Jin, J. Wang, J. Tong, J. Ma and Q. Fang, RSC Adv., 2013, 3, 23128.

18 Y. Wang, J. Sun, K. Jin, J. Wang, C. Yuan, J. Tong, S. Diao, F. He and Q. Fang, RSC Adv., 2014, 4, 39884.

19 Y. Cheng, W. Chen, Z. Li, T. Zhu, Z. Zhang and Y. Jin, RSC Adv., 2017, 7, 14406.

20 F. He, K. Jin, J. Wang, Y. Luo, J. Sun and Q. Fang, Macromol. Chem. Phys., 2015, 216, 2302.

21 L. Kong, Y. Cheng, Y. Jin, Z. Ren, Y. Li and F. Xiao, J. Mater. Chem. C, 2015, 3, 3364.

22 X. Zuo, R. Yu, S. Shi, Z. Feng, Z. Li, S. Yang and L. Fan, J. Polym. Sci., Part A: Polym. Chem., 2009, 47, 6246.

23 J. Wang, C. Lu, Y. Liu, C. Wang and F. Chu, Ind. Crops Prod., 2018, 124, 244.

24 J. Yu, Y. Liu, X. Liu, C. Wang, J. Wang, F. Chu and C. Tang, Green Chem., 2014, 16, 1854.

25 X. Yan, Z. Zhai, Z. Song, S. Shang and X. Rao, Ind. Crops Prod., 2017, 108, 371.

26 C. Lu, J. Yu, C. Wang, J. Wang and F. Chu, Carbohydr. Polym., 2018, 188, 128.

27 Q. Li, X. Huang, H. Liu, S. Shang, Z. Song and J. Song, ACS Sustainable Chem. Eng., 2017, 5, 10002.

28 F. He, K. Jin, Y. Wang, J. Wang, J. Zhou, J. Sun and Q. Fang, ACS Sustainable Chem. Eng., 2017, 5, 2578.
29 V. Singh, S. Joshi and T. Malviya, Int. J. Biol. Macromol., 2018, 112, 390.

30 P. Carbonell-Blasco, M. M.-M. José and I. Antoniac, Int. J. Adhes. Adhes., 2013, 42, 11.

31 B. Liu, J. Nie and Y. He, Int. J. Adhes. Adhes., 2016, 66, 99.

32 R. A. El-Ghazawy, A. M. El-Saeed, H. I. Al-Shafey, A. M. AbdulRaheim and M. A. El-Sockary, Eur. Polym. J., 2015, 69, 403.

33 K. Huang, J. Zhang, M. Li, J. Xia and Y. Zhou, Ind. Crops Prod., 2013, 49, 497.

34 H. Wang, X. Liu, B. Liu, J. Zhang and M. Xian, Polym. Int., 2009, 58, 1435.

35 H. Wang, H. Wang and G. Zhou, Polym. Int., 2011, 60, 557.

36 X. Xu, Z. Song, S. Shang, S. Cui and X. Rao, Polym. Int., 2011, 60, 1521.

37 G. Liu, G. Wu, J. Chen and Z. Kong, Prog. Org. Coat., 2016, 101, 461.

38 Q. Ma, X. Liu, R. Zhang, J. Zhu and Y. Jiang, Green Chem., 2013, 15, 1300.

39 K. Ohba, J. Photopolym. Sci. Technol., 2002, 15, 177-182.

40 G. Maier, Prog. Polym. Sci., 2001, 26, 3.

41 Y. Watanabe, Y. Shibasaki, S. Ando and M. Ueda, Polym. J., 2006, 38, 79.

42 S. J. Martin, J. P. Godschalx, M. E. Mills, E. O. S. Ii and P. H. Townsend, Adv. Mater., 2000, 12, 1769.

43 T. Fang and D. A. Shimp, Prog. Polym. Sci., 1995, 20, 61.

44 C. Yuan, K. Jin, K. Li, S. Diao, J. Tong and Q. Fang, Adv. Mater., 2013, 25, 4875.

45 J. Wan, J. Zhao, B. Gan, C. Li, J. Molina-Aldareguia, Y. Zhao, Y. T. Pan and D. Y. Wang, ACS Sustainable Chem. Eng., 2016, 4, 2869.

46 M. Hardimana, T. J. Vaughanb and C. T. McCarthya, Compos. Struct., 2017, 180, 782.

47 M. R. Vanlandingham, J. S. Villarrubia, W. F. Guthrie and G. F. Meyers, Macromol. Symp., 2001, 167, 15. 